\title{
Building today's platform company
}

\author{
Guido Lanza
}

For entrepreneurs developing innovative technology, the platform business model is making a comeback.

O ver the past 20 years, technology-focused platform companies based on partnering business models have come and gone, somewhat cyclically, as large companies and investors bought into their vision and promise only to become disillusioned by their inability to deliver broad solutions or the rapid commodification of the central technology. As a result, customers and investors abandoned platform companies, and those companies in turn abandoned partnering business models in favor of product-focused companies.

It has become clear, though, that there remains a need for technology-focused platform companies that are uniquely positioned to drive process innovation in the pharmaceutical industry, which continues to suffer from an invention crisis, marked by increasing R\&D costs and a declining number of new chemical entities approvals. This crisis has created an opportunity to develop technologies that address both the inefficiency of discovery and the attrition of new chemical entities through development failures, and these technologies are unlikely to originate within large pharmaceutical companies. This is an opportunity for you if you have the right technology and the right business model. Below, I provide a guide to the key aspects of a platform company, based on my experience at Numerate, a venture that has developed an in silico drug engineering process for reducing the cost, time and risks associated with small molecule drug discovery.

\section{Are you a platform company?}

First, you must decide if you are truly a platform company (Fig. 1). To determine this, here are certain key criteria that all successful platform companies must meet:

Broadly applicable technology addressing an

Guido Lanza is CEO of Numerate Inc., San Bruno, California, USA.

e-mail:info@numerate.com

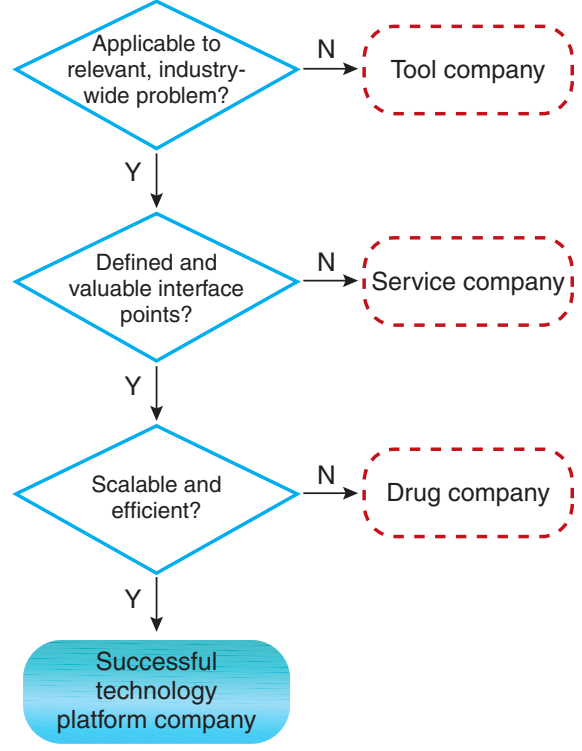

Figure 1 What are you?

industry-wide problem. Your approach needs to gain widespread adoption across therapeutic areas. Very specialized or non-critical path solutions result in small, albeit potentially interesting, tool businesses. These should not be confused with a platform company. For example, technologies applicable only to a small set of proteins, or docking technologies that only generate hints or explanations for medicinal chemists to use, are unlikely to form the basis of valuable platforms.

The technology provides an alternative to existing processes. Your technology should provide a more efficient and/or less risky alternative for reaching value inflection points in the traditional R\&D process. There should also be an easily defined interface between the technology and one or more existing steps in the process. For example, a platform company could substitute the process of advancing from hit to lead, from in vivo models to clinical development candidate selection or from pharmacogenomics data to clinical trial design. If the technology is an add-on to the existing process, requires nonstandard preceding steps or produces output that does not have a clear path forward, then it may form the basis of a service business, not a successful platform company.

The technology scales and provides greater efficiency. Your technology should be efficient, scalable and applicable to multiple projects without requiring large amounts of up-front capital. Those technologies requiring substantial initial capital to drive programs forward may be best suited for product-focused, traditional drug companies- they are not likely to lead to a successful platform technology. For example, a technology for the design of anti-infective compounds that overcome drug resistance is valuable but not scalable. Successful implementation of that technology would likely require significant up-front investment and require a traditional product-focused biotech business model.

\section{Now stay one!}

If you meet the above three criteria, you've got the basis for a platform company. Next, you must make the difficult choice between building a horizontal business by partnering with companies and building a vertical business by picking one or more product opportunities to develop. You cannot do both of these because they cannot be built in the same company, in parallel, for the following two reasons: investors perceive a multiplication of business risk, and partners perceive potential competition from the company's internal product development efforts. Also, importantly, these two routes require different teams, financing models and strategies. You must choose a product-development business model or a partnering business model.

Often, if a company is trying to be a platform firm and chase products of its own, then the high costs, risk and potential upside of the product-development program quickly com- 


\section{Box 1 Presenting yourself}

How you present your technology and to whom is critical to finding and forging successful partnerships. To maximize your chances, focus on these points in your presentation to potential partners.

Start with the business proposition. "My company can solve problem $\mathrm{X}$ by providing solution Y" (but be brief). Or, "My company seeks a partnership from point A to deliver B." And you must include this: "We expect to be paid in manner C." Emphasize the value added, not the clever science, and certainly not how little it costs!

Identify the right individuals in the target company to hear your presentation. The decision to accept your platform is ultimately driven by whether it solves an important problem for one or more individuals in the room. These decisions are more likely driven by career risk than industry-wide or even company-wide needs. So don't waste time selling to the people who run the traditional inefficient or risky process that you hope your technology will replace or improve; they will not be receptive. Instead, target your presentation to those who depend on the existing process to succeed in a larger context-they will almost certainly be interested in your new approach.

Do not craft the traditional presentation that builds slowly to a grand finale. This 'movie script' approach is more likely to bore the audience than to produce the standing ovation it seems intended to obtain. Instead, you must answer the "so what?" question with every piece of information you present, making sure you address the potential partner's interests at every step.

pel the company to focus all of its effort on one product opportunity (or a few) at the expense of the technology platform. Management assumes that if the first project hits, there will be plenty of opportunity (and money) to advance the technology. But it never works out that way. Either the platform is rendered obsolete via continuing advances by other companies who are more platform focused, or the product 'opportunity' ultimately consumes the company, usually for reasons unrelated to the platform. Let's face it-most products fail, leaving the company no choice but to cease operations regardless of the real value of the platform. Or, in the rare case that the product succeeds, the company then focuses on that project and the platform becomes largely irrelevant.

It's also tempting to emphasize the platform first and then branch out into a product opportunity. This is also quite likely to fail. This model involves first partnering the technology to obtain sufficient validation and revenue to support building a pipeline and, in essence, treats partnering as a necessary evil en route to building long-term value. In this model, the risk is even higher because to gain overall success, both aspects need to succeed.

The truth is, partnering is the only real business opportunity for a technology platform company. Here are several reasons why:

Competitive advantage. A partnering-focused business model best exploits the competitive advantage provided by a technology platform. Every dollar is spent on increasing the technological lead, not on advancing a high-risk product candidate. In fact, focusing on developing products effectively transforms the company's competitive advantage - the platform - into an added expense and distraction. Competitors for those same drug targets do not have that distraction.

Risk reduction. Partnering allows you to assume only those business (and career) risks that the technology mitigates. Although every technology has its inherent risks, the fact that you created your technology platform means you can best mitigate those risks. Moreover, a focused technology is far less risky than drug discovery, development and commercialization. By reducing your risks and focusing your technology on a small part of the overall discovery-tocommercialization process, you and your company can become successful. For example, even the best hit-finding technology does not address downstream risks of adsorption, desorption, metabolism, excretion or toxicity, which are assumed when building a product-focused company.

Avoid dependence on equity dollars. It's more difficult than ever these days to attract venture financing, regardless of business model. But a successful partnering business generates early revenues that can fund the cost of perfecting the technology platform and increase the company's technological lead over its competition. In contrast, the development of a drug requires a large investment, which means you need to raise equity and dilute founder and initial investor ownership, and you will lose the ability to continue development of the technology platform.

\section{Convincing others}

Given the market's skepticism toward overpromising and under-delivering platform technology companies, starting a partneringfocused business around a new technology platform today is more challenging than building the technology platform itself. The early stage of business development presents a number of chicken-and-egg problems for initial financing and early revenue generation: you need to build and validate the platform to attract investors or partners, but building and validating the platform actually requires funding from investors or partners. You must be unusually vigilant in avoiding the temptation to perfect the technology before leaving the lab to get feedback and funding from customers and investors. The simplest version of the platform that provides the easiest route to a differentiating proof of concept should be enough to gain traction with rightfully skeptical (but potentially visionary) partners. Those partners then lower the perceived risk for investors.

Also, you do not need the ultimate ideal customer to provide validation. Your first few deals should emphasize science and validation, not economics. In fact, even a small, academic partnership can be preferable to the big pharma deal, especially when the latter completely consumes the company's bandwidth and carries with it dangerous terms like broad and/or multiyear exclusivity. In addition, the platform is likely not to work perfectly in every case, so you might be better off using small deals to work out problems and limitations. Once you've scored some partners and earned validation, it will inspire confidence that the platform will deliver on its promise and will lead to better terms and structure with subsequent partners.

\section{Attracting customers}

The reality is that there are two kinds of customers: ones that take a long time to accept the value of a technology and early adopters. The challenge is to find the early adopters fast. From the outset, you need to understand the structure of the industry around you. Ask yourself the following questions:

What is the $R \& D$ process that interfaces with your technology platform? What are the preceding and succeeding steps? Early adopters are likely to be those who can understand the benefit of using your platform to remove a specific bottleneck.

Who supplies what to whom? If you were not there, where else would they get the output of the platform? Would it be internal R\&D or an external source? Given the amount of investment in the existing process, the barrier for adoption will 
be lower for those who currently rely on partners or vendors.

What pieces of the value chain are replaced or improved by the technology platform? The platform should encompass a step function in terms of the value being generated (taking a hit to a lead, taking a lead to a candidate and so forth). Early adopters are likely to be companies that capture the most value from reaching that next point—for example, a lead for an academic, a drug candidate for a smaller biotech or a clinical compound for a large pharma company.

The answers to these questions provide the map that defines the universe of potential early adopters for the technology platform. Even so, there is no substitute for testing your hypothesis regarding early adopters versus later-stage customers. Early on, you need to get in front of as many potential partners as possible to understand who needs the technology and how much to charge for access. There is no single way to conduct this market research: cold calls, introductions from advisors, and investor and partnering meetings are all great ways to approach partners.

When presenting to potential partners (Box 1$)$, ask about their R\&D process, and treat the meetings as market research opportunities first and sales opportunities second. To ensure an interactive meeting, keep your presentation brief and pepper the partner with questions. These meetings can help you determine whether the platform is a good fit for the potential partner and how to present the opportunity better to the next person.

Once a set of early adopters has been identified, you can go for a more traditional sales process. You might want to present the technology in painful detail, but a high level of technological detail will most likely bore or confuse people unfamiliar with the technology. Detailed technology analysis is best saved for due diligence after both sides agree that mutual interest and benefit exists. And don't worry about giving away key information in due diligence-being perceived as coy or overly protective about confidential information can lead to distrust. If the technology platform is truly advanced, then it is highly unlikely that a potential partner, even in due diligence, could learn enough to reproduce and exploit the technology without further help. The fewer 'trust me' moments there are in due diligence, the more likely a partnership will result.

\section{The deal}

Once you have interest, the process of pricing and structuring the deal begins. Successful negotiations focus on value, not price. Sophisticated partners will not accept at face value your enthusiastic claims, so fill the credibility gap in due diligence. Success-based payments can be the key to bridging any remaining gap. Although deal structures for drug product opportunities are well established for the different stages of drug development (and for medical device and diagnostic opportunities), deal structures for an innvoative technology platform often have to be defined by you.

In general, a technology platform deal will have most or all of the following components:

Up-front payment. With money paid up front, your partner pays just for the privilege of working with you. It is the risk that you ask the partner to assume. The amount will be driven by the perceived risk and benefit of adopting the technology platform. Validation (directly related to the likelihood of achieving the promised deliverable) will determine the up-front payment amount. Instead of simply lowering the up-front for early adopters, try to assume the perceived risk without significant valuation loss with early success milestones. Avoid lowering the up-front so much that you eliminate real buy-in from the partner.

R\&D support. Your partner will also need to supply funding to support your R\&D head count and expenses. Often, to deliver on the partnership objectives, the platform company may need to take on some project-specific costs. If you are trying to build a deal around the value of the platform's deliverable, then R\&D support should be the only cost-related term, and you should not include general platform-building costs. From the partner's perspective, the R\&D support cost will be viewed as a deferred upfront payment and a pre-success assumed risk, so it too will greatly depend on the validation existing at the start of the partnership. To close a deal during the early stage of business growth, consider deferring R\&D support until after one or more early milestones provide additional validation for your technology.

Delivery (success-based) milestones. Delivery milestones are paid once you demonstrate and provide tangible benefit to your partner. These milestones presume success, so their amounts must and should be decoupled from the validation your technology enjoys (or not) at the start of a partnership. By definition, if a delivery milestone has been met, then the platform has delivered value, and the milestone amounts should be driven more by what it would have cost the partner to get to that milestone or buy that deliverable on the market than on what it cost you. To get to a deal quickly, the best way to price milestones is to make payments significantly cheaper than these potential partner costs.
Downstream (partner-dependent) milestones and royalties. Downstream milestones are paid when a partner achieves a result based on a deliverable you provided but using its own resources subsequent to the delivery of your last deliverable (the 'drop-off' point). These milestones should be some relatively small fraction of what the partner would have paid to in-license a similar product at that milestone point. The amount must directly reflect only the demonstrated contribution made by your technology to reach that point. For example, if the patents and applications filed as a result of your contributions cover the product that reaches a downstream milestone, then you have sound justification for asking for higher milestone payments. These downstream milestones are usually viewed as punitive, even in the best of circumstances, so your initial proposals for them cannot be disproportionate or you may lose the opportunity to do a deal.

Ownership. Discussions of who owns what technology have derailed many potential partnerships. Make sure to keep business control of these meetings. Although you need legal advice on crafting contractual language, do not let the lawyers take control of the discussions. If you are running a technology platform company, then you need to own your technology, not your partner's products. By ensuring that your partner has exclusive ownership of its products and that you have access to technology improvements resulting from the partnership, you should be able to reach mutual agreement on ownership provisions efficiently.

\section{It's not 1999 , but it can be done}

The pharmaceutical R\&D environment has changed dramatically since 1999, the last time platform companies enjoyed commercial success. Demand has shifted from technology that produces new opportunities to technology that makes the R\&D process more efficient and predictable. The economic hard times have created an opportunity for new technology platforms, as companies dependent on successful R\&D become ever more focused on reducing costs and therefore are more open to adopting innovative technologies. In 2009, entrepreneurs with broadly applicable, efficient alternatives to current processes not only can but should build partnering-based businesses around such innovative technologies. Use the partnering-focused business model to minimize risk and go hunt partners.

To discuss the contents of this article, join the Bioentrepreneur forum on Nature Network: http://network.nature.com/groups/bioentrepreneur/forum/topics 